\title{
Da "Guerra" no Complexo do Alemão à Ocupação da Favela Santa Marta: aspectos de uma política de segurança pública
}

\author{
Luis Claudio Palermo ${ }^{1}$ \\ Universidade do Estado do Rio de Janeiro (UERJ), RJ, Brasil \\ E-mail: luisclaudio72@gmail.com
}




\section{Resumo}

A política de segurança pública do governo Sérgio Cabral (2007-2014) foi marcada, no plano geral, por dois momentos distintos: na primeira fase, prevaleceu uma orientação belicosa; na segunda, predominou uma ênfase na ocupação de favelas para instalação de Unidades de Polícia Pacificadora (UPP). A partir de parcela importante da mídia impressa, serão analisados alguns aspectos dessa política de segurança, a fim de comparar pontos importantes presentes nos dois momentos supracitados, bem como mostrar representações das favelas do Complexo do Alemão para o governo. Com base em informações e nos debates estruturados pela imprensa escrita, o artigo procura mostrar o quanto houve uma convergência entre representação social do Alemão e as ações policiais violentas na região. Por consequência dessa experiência prática, visa-se mostrar certos elementos de continuidade entre as duas fases já mostradas: a da "guerra" e a da "pacificação". Como suporte orbital da análise desses fenômenos, intenta-se situar o papel político da mídia.

Palavras-chave: Segurança Pública. Representações. Mídia Impressa. Unidades de Polícia Pacificadora. Favelas Cariocas.

\section{Abstract}

The public policy of the government security Sérgio Cabral (2007-2014) was marked in the general plan, by two distinct periods: the first phase, a bellicose orientation prevailed; the second, an emphasis on the predominant occupation of slums for installation of Unidades de Polícia Pacificadora (UPP). From major portion of the print media, some aspects of this security policy will be analyzed in order to compare important points present in the two aforementioned moments, as well as showing representations of the favelas of Complexo do Alemão for the government. Based on information and discussions structured by written press, the article attempts to show how there was a convergence between social representation of Complexo do Alemão and violent police actions in the region. Consequently this practical experience, we aim to show certain elements of continuity between the two phases shown above: a "war" and "peace". As a orbital support of the analysis of these phenomena, the article tries to situate the political role of the media.

Keywords: Public Safety. Representations. Print media. Unidades de Polícia Pacificadora. Pacifying. Carioca slums. 


\section{Introdução}

Governador Sérgio Cabral esteve no comando do Estado do Rio de Janeiro no período de janeiro de 2007 até abril de 2014. Desde o começo dessa gestão, a segurança pública foi estabelecida como um dos principais focos (O Globo, domingo, $1^{\circ}$ julho, 2007, p. 17). Assim, a política de segurança do governo, sobretudo em sua fase inicial (ano de 2007), foi desenvolvida tanto através de "declarações enfáticas de guerra às facções criminosas" (Machado da Silva, 2010, p. 2), como por meio do combate efetivo e violento aos traficantes que controlavam o comércio de drogas em algumas favelas cariocas. (Alves; Evanson, 2013, p. 51-144)

A tônica de tal política pode ser exemplificada a partir das inúmeras notícias divulgadas sobre as ações policiais nas favelas dos Complexos do Alemão e da Penha - que doravante serão tratados apenas como Alemão, a fim de facilitar a exposição - assim como pelas declarações de representantes do alto escalão do governo à imprensa. Segundo Machado da Silva, a metáfora da "guerra ao crime" foi transformada, nesse contexto, em política pública oficial (Machado da Silva, 2010, p. 1). Em razão da repercussão negativa decorrente de tais ações, o governo procurou fazer adequações em suas declarações, mas manteve o foco combate violento aos grupos de criminosos que controlavam a venda de drogas em algumas favelas do Rio de Janeiro.

Em síntese, a mudança mais visível ocorreu com a ocupação policial da favela Santa Marta, em Botafogo, quando cerca de cento e trinta policiais militares entraram na localidade, a partir de dezenove de novembro de 2008. Essa ocupação deu origem à criação de uma Companhia de Policiamento Comunitário, em 19 de dezembro de 2008 
(O Globo, domingo, 28 dezembro, 2008, p. 15). No início do ano de 2009, o governo planejou a expansão desse modelo de policiamento que acabou sendo batizado de Unidades de Polícia Pacificadora (UPP) (Fleury, 2009; Burgos et al., 2011). Desde então, o modelo tem sido expandido e tem conquistado crescente visibilidade, notadamente na (e através da) imprensa.

Com base em dados oficiais, cumpre esclarecer que uma UPP corresponde a "[...] uma pequena força da Polícia Militar com atuação exclusiva em uma ou mais comunidades" (Rio de Janeiro, 2013a). Então, por essa perspectiva, a favela "Santa Marta foi a primeira experiência da política de aproximação entre polícia e comunidade idealizada pela Secretaria de Segurança do Rio de Janeiro" (Rio de Janeiro, 2013b). Nesse sentido, as UPPs:

[...] trabalham com os princípios da polícia de proximidade, um conceito que vai além da polícia comunitária e que tem sua estratégia fundamentada na parceria entre a população e as instituições da área de segurança pública. A atuação da polícia pacificadora, pautada pelo diálogo e pelo respeito à cultura e às características de cada comunidade, aumenta a interlocução e favorece o surgimento de lideranças comunitárias. (Rio de Janeiro, 2013b)

Em função do que foi exposto, pode-se propor que as UPPs nasceram, em resumo, "[...] como resultado invertido da truculência retórica, que exagerava no reconhecimento explícito do que secularmente acontece nos bastidores do controle das 'classes perigosas', que sempre se realizou através da violência” (Machado da Silva, 2010, p. 2-3). Em outros termos:

[...] a UPP efetivamente demarca uma inflexão na politica de segurança pública do governo do Estado que, até então, havia sido marcada por operaçôes policiais violentas e letais, que tiveram seu momento mais dramático na (primeira) ocupação do Complexo do Alemão em Junho de 2007, episódio também conhecido como Chacina do Pan, em que 19 pessoas foram mortas, muitas delas com indícios de terem sido executadas. (Burgos et al., 2011, p. 52, grifos nossos) 
Ainda que tenha marcado uma mudança na política de segurança pública do governo do Estado, convém ponderar, por outro ângulo, que as UPPs foram criadas sem uma direção precisa e claramente definidas, surgindo como resultado das injunções conjunturais e como fruto de uma aprendizagem institucional (Fleury, 2012, p. 199). Foram construídas, portanto, em razão do processo histórico de transformação da cidade do Rio de Janeiro que contemplou a preparação da cidade para os megaeventos (Palermo, 2013) e para receber investimentos sociais de grande monta, como, por exemplo, os do Programa de Aceleração do Crescimento (PAC). Para tanto, a parceria entre os governos Federal, Estadual e Municipal foi de grande importância, bem como as diretrizes balizadoras do Pronasci - Programa Nacional de Segurança Pública com Cidadania (Alves; Evanson, 2013). Dessa forma, segundo Fleury:

O fato da cidade do Rio de Janeiro ter sido escolhida para sediar, proximamente, megaeventos como as Olimpíadas e a Copa do Mundo colocou em questão a capacidade governamental de reduzir a violência e exercer o controle efetivo sobre seu território. Fruto deste contexto e da aprendizagem, e inspirada em experiências internacionais de ocupação territorial e integração como de Medellín, surge a primeira UPP, depois da ocupação militar no Santa Marta em 2009. Sem uma estratégia inicial claramente delineada, esta primeira experiência foi considerada emblemática para construção e posterior aplicação desse modelo de pacificação, caracterizado pela ocupação territorial, existência de fortes vínculos entre agentes governamentais e empresariais, desenvolvimento de programas de formalização do mercado e promoção social. (Fleury, 2012, p. 199, grifos nossos)

Tendo em vista o que foi exposto, o ponto de partida adotado neste artigo se baseia em duas premissas: a primeira é que as UPPs foram inventadas, segundo o próprio Secretário de Segurança Pública, José Mariano Beltrame, como um "laboratório" (O Globo, Quarta-Feira, 3 dezembro, 2008, p. 13), logo não havia uma orientação precisamente estruturada; a segunda é que este projeto foi criado como fruto de um contexto histórico e da aprendizagem do governo, aprendizagem tanto no que remetia a outros modelos de segurança, como no tocante ao 
cotidiano da condução de sua política de segurança pública, conforme discutido adiante.

Visando apresentar e analisar uma perspectiva da política de segurança do governo em questão, neste artigo exponho e analiso o conteúdo de matérias de jornais impressos que remetem a dois momentos específicos da referida gestão governamental: o primeiro é concernente ao ambiente que envolveu as ações policiais na fase inicial do governo, no ano de 2007, tendo como foco algumas operações realizadas no Alemão; o segundo refere-se aos discursos que estruturaram as ações que foram colocadas em prática na ocupação da favela Santa Marta, com vistas à criação de uma Companhia de Policiamento Comunitário, em novembro e dezembro de 2008, que, no início do ano seguinte, transformou-se em UPP.

Como desdobramento, pretendo cumprir dois objetivos principais: (i) colocar em destaque, a partir da imprensa, de que maneira o Estado (e a imprensa também) representava socialmente as favelas do Alemão, qualificando-as como lugar de perigo imediato e de alta intensidade (Machado da Silva, 2012, p. 62), bem como mostrar em que medida tal representação espacializada do Alemão como território da violência contribuiu para motivar intervenções policiais violentas na região, o que corresponde a um "[...] claro exemplo do encontro entre representação, construção de problemas públicos e políticas de intervenção [...]" (Machado da Silva; Leite, 2008b, p 50); (ii) imbricada à primeira questão, apontar em que medida há - com base no que foi selecionado, hierarquizado e publicado pelos veículos de imprensa pesquisados - alguns elementos de permanência na política de segurança referente aos dois períodos selecionados. Dessa forma, não obstante o fato de "[...] a UPP efetivamente demarca[r] uma inflexão na política de segurança pública do governo do Estado" (Burgos et al., 2011, p. 52 ), pretendo mostrar em que medida tal mudança se aproveitou de experiências relacionadas às ações anteriores à efetiva inflexão, bem como colocar em discussão, de forma lateral, até que ponto a imprensa interfere nessa construção. 


\section{Apontamentos Metodológicos}

Este artigo é estruturado a partir de informações divulgadas por parcela importante da grande imprensa ${ }^{2}$ acerca dos primeiros anos da política de segurança do governo Sérgio Cabral, o que corresponde aos jornais $O$ Globo, Extra e Expresso (especialmente o primeiro e o segundo), periódicos de grande circulação no Estado do Rio de Janeiro. Devo destacar que o acesso ao material foi conseguido em razão de minha participação numa pesquisa ampla sobre as UPPs ${ }^{3}$. Cumpre registrar que as interpretações contidas no artigo são de minha responsabilidade.

É importante destacar que a visibilidade crescente das UPPs na sociedade é fruto, também, de sua aparição constante na mídia. Desde a primeira ocupação policial realizada na favela Santa Marta, uma parcela destacada dos veículos de comunicação começou a pautar as ocupadas de outra forma, sobrelevando a perspectiva da "paz" em detrimento da "guerra", produzindo sentidos sociais sobre a rotina desses lugares de moradia e suas representações na cidade. Dessa forma, a mídia impressa selecionada, na qualidade de um recorte relevante de tais veículos de comunicação, é o canal que propicia a discussão estabelecida neste artigo. Logo, devo alertar que é nesse âmbito da vida social e política que os resultados aqui apresentados e discutidos devem ser vistos, analisados e debatidos. Portanto, ao examinar essa dimensão da vida social e política, chamo a atenção dos interlocutores para o limite do olhar do pesquisador ao utilizar a imprensa como fonte. (Fausto Neto, 1999, p. 13)

Saliento, por outro lado, que o trabalho com as mídias é dotado também de riqueza e possibilidades interessantes (De Luca, 2011, p. 129), pois ela é efetivamente parte integrante da vida social e política. Para o acompanhamento e exame crítico do conteúdo das matérias dos jornais, dois pontos coordenaram a análise: (i) a mídia seleciona e hierarquiza informações que serão publicadas (Silva, 2010, p. 85110; Fausto Neto, 1999, p. 23), assim é capaz tanto de definir pautas de discussão públicas sobre o tema da segurança (Rondelli, 2000, p. 156; Fausto Neto, 2004), quanto funcionar como um sistema leitor para a sociedade (Fausto Neto, 2004; Silva, 2010), pois sua abordagem contribui para criar uma interpretação bem visível de um aconteci- 
mento. Esse processo é orientado por seu próprio interesse editorial e/ou de seus patrocinadores (Bourdieu, 1997, p. 19-20), levando em conta também seu público-alvo, seus leitores (Silva, 2010, p. 154-158; Fausto Neto, 1999, p. 12-13). Como consequência, a mídia tem a capacidade de agir "[...] sobre o espaço político, evocando a si, muitas vezes, a condição de um poder a partir do qual põe em funcionamento estratégias de onde se aponta os caminhos e os destinos da política e dos seus atores" (Fausto Neto, 2004, p. 120); (ii) ademais, a mídia é um "[...] dispositivo de representação do que se passa na cena política" (Fausto Neto, 2004, p. 120), ou uma construtora privilegiada de representações sociais (Borges, 2004) cujo trabalho acaba tendo, por conseguinte, um papel político. (Silva, 2010, p. 163)

Diante do exposto, as supracitadas características relativas à atuação das mídias foram pensadas, metodologicamente, como sendo capazes de forjar um constructo discursivo que, além de apresentar e representar a política de segurança pública, também influencia, por outro lado, a própria ação governamental. Portanto, a análise da chamada "[...] cobertura de segurança pública" (Silva, 2010, p. 159) que é realizada pela imprensa escrita pode fornecer, por sua característica de maior detalhamento em relação a outras mídias (Borges, 2004, p. 148; Silva, 2010, p. 36-46), novas informações e apresentar outras perspectivas acerca da política de segurança do governo em apreço. Para os termos deste artigo, a fonte selecionada é pensada e organizada como uma determinada perspectiva dessa política de segurança, de modo que assim a fonte selecionada possa fornecer subsídios para se discutir tanto os elementos de permanência/mudança dessa política, quanto para o entendimento da estruturação do Alemão como um lugar de perigo.

Reitera-se que não se trata de tomar o discurso das mídias estudadas - ou os que foram publicados por elas - como construtor de uma "verdade", mas sim de por em tela este viés social e político, uma vez que os veículos estudados são parte integrante da cena social cotidiana e, ademais, “[...] as ações de políticas públicas [também] são formuladas e executadas por essa esfera [os jornais]" (Fausto Neto, 1999, p. 137). Trata-se, então, de uma perspectiva sobre as 
representações sociais e ações políticas que pode cooperar para que se suscitem outros questionamentos e olhares acerca da política de segurança do referido governo do Rio de Janeiro, bem como sobre a construção das UPPs.

\section{Janeiro a Abril de 2007: as primeiras ações do governo no campo da segurança pública}

A segurança pública foi escolhida como um dos princípios basilares do governo em apreço, desde seu início, ou seja, a partir de janeiro de 2007. Ao analisar matérias dos jornais escolhidos, referentes aos primeiros meses dessa gestão, percebe-se o quanto o campo da segurança, especialmente o combate ao tráfico de drogas que ocupa favelas cariocas, foi um dos focos do governo. Isso foi declarado pelo governador ao jornal $O$ Globo, ainda em meados do ano de 2007. Perguntado se a segurança continuaria o foco do governo, Sérgio Cabral disse: "Este é o eixo do nosso governo". (O Globo, domingo, $1^{\circ}$ julho, 2007, p. 17)

As ações policiais em favelas cariocas foram, no referido governo, objeto constante da mídia. Com isso, ela estruturava e apresentava publicamente a relação do poder com alguns desses lugares de moradia. Nesse período, com base nas notícias, é lícito afirmar que o Alemão foi eleito como um dos focos principais da política de segurança do governo, visto que, de maneira crescente, a região foi recebendo operações policiais. Isso reverberou no aumento gradativo de matérias jornalísticas que divulgavam as ações violentas da polícia contra criminosos que controlavam o comércio de drogas no local.

As primeiras ações nas favelas do Alemão foram apresentadas como resposta do governo a uma onda de ataques violentos que ocorreram na cidade do Rio de Janeiro, no fim do ano de 2006, ou seja, antes do citado governador ter assumido cargo. Foi relatado que, nesses episódios violentos, grupos de criminosos dispararam tiros em delegacias, postos de policiamento, cabines da polícia militar e prédios públicos, nas zonas Norte, Oeste e Sul da cidade. A imprensa noticiava que o serviço de inteligência do governo havia concluído que os criminosos tinham como base de atuação a localidade em questão. 
Começaram a ser realizadas, então, ações policiais mais sistemáticas nessa região. Como exemplo elucidativo, no mês de fevereiro, O Globo noticiava uma operação que contou pela primeira vez com o apoio da Força Nacional de Segurança Pública (FNSP). Tratou-se de uma operação conjunta que contou com a união de forças Federais e Estaduais, conforme visto no título da matéria a seguir: "Força Nacional faz primeira operação em favela, ao lado da Core [Coordenadoria de Recursos Especiais] e do Bope [Batalhão de Operações Especiais]". (O Globo, quarta-feira, 14 fevereiro, 2007, p. 16)

Por outro lado, não tardaram a surgir insatisfações dos moradores das favelas da região quanto à política de segurança combativa que, no governo em questão, começava a orientar as ações policiais nessas localidades. A imprensa não deixou de mostrá-las, ainda que com menor destaque do que as ações planejadas pelas forças estatais, privilegiando, dessa forma, o ponto de vista normativo das operações. Destarte, na mesma matéria em que cita a primeira intervenção num conjunto de favelas cariocas da FNSP, O Globo informou, como subtítulo, que o "Confronto no Alemão deixa 6 mortos e provoca protesto de moradores" (O Globo, quarta-feira, 14, fevereiro, 2007, p. 16). Essa operação hierarquizante pode ser caracterizada como "construção do 'lugar do jornal', a partir do modo pelo qual ele referencia o acontecimento". (Fausto Neto, 1999, p. 57)

As justificativas concernentes às primeiras incursões na região passavam a apontar para o desmantelamento de um possível paiol que era mantido pelo grupo de criminosos que se estabelecia na localidade. Nesse sentido, o governador Cabral declarou o seguinte: "Procuramos um paiol de guerra no Alemão, onde há dois anos e meio não se fazia uma operação policial. Temos que combater o crime de maneira inteligente, vamos sufocar o tráfico" (Quinta-Feira, 15, fevereiro, 2007, p. 12). Pelas palavras da principal liderança do governo fluminense à imprensa, já se podia notar uma preocupação especial com o Alemão. A operação foi dada como encerrada sem que se encontrasse o suposto paiol.

Mais uma vez, moradores da região, apoiados por organizações de defesa dos direitos humanos, fizeram uma espécie de protesto, através de "[...] uma nota criticando a operação no complexo" (Extra, sexta- 
feira, 16, fevereiro, 2007, p. 12) porque, segundo relatou a imprensa, eles alegaram que "a ação contrariou o compromisso firmado entre os governos estadual e federal por uma nova política de segurança pública" (Extra, sexta-feira, 16, fevereiro, 2007, p. 12). Entretanto, a divulgação no jornal teve visibilidade secundária (no final da matéria), em comparação com a execução das ações policiais, que apareceram em primeiro plano, ou seja, no topo da matéria e na sua descrição inicial.

É importante realçar que, gradativamente, começaram a brotar nos periódicos novas razões que explicavam o foco combativo do governo nas favelas da região. Isso pode ser observado na matéria que finalmente abordava que havia sido encontrado o mencionado paiol. “Cerca de 460 policiais civis e militares estouraram ontem um superpaiol no Complexo do Alemão, considerado o entreposto da maior facção criminosa do Rio" (O Globo, quarta-feira, 7, março, 2007, p. 16, grifos nossos). A partir da leitura diária das notícias relacionadas à região, nota-se que o foco da política de segurança do governo parecia se concentrar cada vez mais na localidade. Assim: O "Alemão é a atual preocupação da Secretaria de Segurança!" (Extra, domingo, 11, março, 2007, p. 28)

Ainda que de forma não sistemática e não constante, as operações policiais na área continuaram a ser mostradas nos jornais, durante o mês de abril. Como exemplo, vale registro para uma incursão realizada na área, a fim de tentar cumprir mandados de prisão contra acusados de terem assassinado um escrivão da polícia federal. Na operação, mais um morador da localidade foi ferido. (Extra, sexta-feira, 6, abril, 2007, p. 10)

Com o alvorecer do mês de maio, as favelas da região figurariam constantemente na imprensa porque houve uma inflexão significativa na orientação prática das ações policiais no lugar (Alves; Evanson, 2013, p. 51-144). Os episódios de maio expuseram importantes elementos para se discutir tanto o modelo de segurança aplicado, como também a situação do Alemão e sua representação social tanto para o governo como para a imprensa. 


\section{A Partir de Maio de 2007: a intensificação das operações policiais de "guerra" no Alemão}

Passados poucos dias do início do mês de maio, os jornais pesquisados começaram a divulgar, com maior destaque e constância, as operações policiais realizadas na região. As notícias mostravam que, a princípio, as ações policiais sistemáticas e recorrentes objetivavam a prisão de criminosos responsáveis pela morte de dois policiais em Oswaldo Cruz, bairro localizado na Zona Norte do Rio de Janeiro. À medida que as operações se intensificam e que eram veiculadas na mídia, é possível entrever outros motivos envolvidos.

As ações policiais nesse conjunto de favelas foram noticiadas quase diariamente e, com isso, os periódicos começaram a expor a quantidade crescente de pessoas mortas e o desrespeito aos direitos elementares dos moradores por parte das forças do Estado (Alves; Evanson, 2013). Dessa forma, cumpre registrar que a mídia passou a iluminar também as diversas insatisfações quanto à alteração da rotina de pessoas que tinham algum tipo de relação com o Alemão, sejam moradores, trabalhadores ou indivíduos que apenas tinham os bairros do entorno como passagem. No entanto, a divulgação desses problemas era feita, não raramente, de maneira secundária em relação às ações policiais.

Não obstante as pressões de instituições de defesa dos direitos humanos ou das pessoas que se sentiam diretamente (ou indiretamente) impactadas com as ações realizadas, o governador e sua equipe ligada à segurança pública mostravam-se, através da mídia, convictos e irredutíveis de suas ações e seus objetivos. Beltrame deu declaração à imprensa na qual justificava as ações citadas por meio de argumentos técnicos. Ele mostrava, ainda, que se previa a ampliação das operações para outras favelas, conforme excerto a seguir:

Tudo tem suporte da inteligência. O Bope (Batalhão de Operações Especiais) não é uma tropa de ocupação permanente. Ele vai continuar a fazer o que tem que ser feito. Estamos planejando novas operações em cinco ou seis comunidades (O Globo, terça-feira, 15, maio, 2007, p. 13). 
Na mesma linha, o governador dava apoio às operações contundentes, valorizando menos os problemas decorrentes das ações policiais e mais a normatividade dos procedimentos técnicos. Assim declarou ele:

Continuaremos não só no Complexo do Alemão, como também em outras áreas onde os criminosos atuam e ameaçam a população. Não queremos baleados, sobretudo vítimas inocentes. Mas não há outro caminho que não seja enfrentar esses criminosos. Não dá para pedir licença ao criminoso para pegar o fuzil dele, para acabar com o seu mando. Há que se ter o enfrentamento. (Extra, quarta-feira, 16, maio, 2007, p. 21)

Os jornais pesquisados, ao divulgarem a ampliação das ações de combate realizadas por instituições governamentais contra facções criminosas que controlavam o tráfico de drogas no Alemão, mostravam que essas ações ganhavam, paulatinamente, novos sentidos. Assim, a justificativa para as recorrentes incursões policiais, que girava em torno da busca aos criminosos que haviam assassinado um policial militar em Oswaldo Cruz, começou a ganhar nova semântica e a ser divulgada pelos jornais como algo que se tornou mais amplo. Tais justificativas tinham seu solo e seu fundamento no combate à criminalidade, em especial à facção criminosa que controlava o tráfico neste complexo de favelas.

A partir das discussões que foram selecionadas e publicadas pela mídia examinada, é lícito, portanto, pensar que o Alemão representava algo de diferente para o governo (e para a mídia que selecionava e publicava tais notícias), pois era situado na cidade, por seus integrantes, como território que centralmente irradiava perigo, sendo o ponto de apoio da principal facção criminosa do Rio, o Comando Vermelho. Isso pode ser visto no trecho a seguir:

Para o secretário, o Complexo do Alemão é o principal foco de disseminação de violência no Rio. Além do tráfico, os bandidos da região alugam armas, atuam em roubos de carros fora da comunidade e em ataques a policiais, como o que resultou na morte de dois PMs, no dia $1^{\circ}$ de maio, em Oswaldo Cruz. (O Globo, quarta-feira, 23, maio, 2007, p. 14). 
Poucos dias depois da declaração do secretário, conforme excerto anterior, o mesmo periódico deu visibilidade à fala do coronel Marcus Jardim, comandante do $16^{\circ}$ BPM (Olaria), à época, que contribui para mostrar a mudança no discurso de justificação das ações. Segundo o jornal:

O coronel [Marcus Jardim] explicou que a operação da PM foi desencadeada para investigar a morte de PMs em Oswaldo Cruz. Mas, ao se deparar com a realidade nos complexos da Penha e Alemão, o objetivo passou a ser também o de desarticular o tráfico e o seu poderio bélico. $(\mathrm{O}$ Globo, domingo, 3, junho, 2007, p. 18, grifos nossos)

Transcorrido pouco mais de quinze dias de ações policiais violentas na região, tendo sido contabilizadas em torno de dezesseis pessoas mortas e mais de cinquenta feridas, segundo os números oficiais, $\mathrm{O}$ Globo divulgava, então, que a "Guerra no Alemão já é [era] o maior confronto do Rio" (O Globo, sábado, 19, maio, 2007, p. 18). Como desdobramento, os jornais começaram a publicar mais intensamente não somente as críticas à violência das operações policiais na localidade e à interferência na rotina dos moradores (Alves; Evanson, 2013, p. 51-116), mas, sobretudo, passaram a por em pauta, de maneira mais contundente, outras propostas para a segurança pública do governo. Cumpre destacar que essas discussões contribuirão para referenciar o ulterior debate sobre segurança que foi estruturado pela imprensa na ocasião da ocupação da favela Santa Marta, em 2008. É muito importante chamar a atenção e alertar que essas propostas elencadas à frente não eram necessariamente inéditas, no que se refere à política de segurança pública do Rio de Janeiro. Eram novas tendo em vista o contexto belicoso que orientou o governo em apreço.

Selecionada e publicada na mídia mais popular das três examinadas, uma das primeiras sugestões capturada na pesquisa foi feita por uma moradora do Alemão que não quis se identificar. Insatisfeita com a constante troca de tiros na região, ela declarou que "As pessoas de bem gostariam que a PM montasse um posto. Vir aqui só para trocar tiros e nos colocar em risco não adianta" (Expresso, terça-feira, 22, maio, 2007, p. 6). Seguindo este percurso, O Globo consultou, poucos dias depois, três especialistas em estratégia militar e segurança. De 
acordo com o jornal, eles foram unânimes em apontar que faltavam "policiais e equipamentos para garantir a ocupação da região" (Expresso, domingo, 27, maio, 2007, p. 30). O então Diretor do Departamento de Estudos Estratégicos da Universidade Federal Fluminense (UFF), Ronaldo Leão, apontou outras questões: “A polícia tem que entrar na comunidade junto com um conjunto de medidas para resgatar e dar perspectiva de vida para a população" (Expresso, domingo, 27, maio, 2007, p. 30, grifos nossos). O vice-presidente do Centro Brasileiro de Estudos Estratégicos, o coronel do Exército Amerino Raposo, corroborou com a análise feita por Leão e, em acréscimo, declarou que:

Não vai adiantar nada ocupar a comunidade apenas com a polícia. Não há efetivo para manter esse tipo de operação por muito tempo. É preciso urbanizar o complexo, transformá-lo num bairro, dar escola, saúde e perspectiva de futuro aos jovens. Caso contrário, o tráfico volta. (Expresso, domingo, 27, maio, 2007, p. 30, grifos nossos)

As pressões dos moradores, inclusive através de realização de manifestações públicas (Extra, sexta-feira, 1으. junho, 2007, p. 13), de algumas instituições de defesa dos direitos humanos, além das indicações dos especialistas em segurança pública e estratégia militar, começaram a ser escolhidas pela imprensa em destaque e a ganhar mais visibilidade pública. Assim, os jornais capturaram, selecionaram e não deixaram de noticiar as referidas pressões, agindo, nesse sentido, como uma espécie de "ator político" (Silva, 2010, p. 135-158) ao organizarem e pautarem novas propostas para a segurança pública. Segundo Silva, ao noticiar, a imprensa está, ao mesmo tempo, denunciando e analisando criticamente uma situação, agindo, portanto, na esfera pública (Silva, 2010, p. 145). Essa ação, no que se refere aos jornais, é realizada a partir do que os jornalistas consideram como "leitor médio", uma vez que o veículo intenta se ajustar ao horizonte de expectativas da grande maioria de seu público-alvo ( Silva, 2010, p. 97). Vale esclarecer que "leitor médio" corresponde a um tipo idealizado de leitor que o jornal quer atender, na medida em que “[...] o público leitor mantém, ainda que não declaradamente, uma relação dialética com o jornal, na qual tanto sofre quanto produz efeitos" (Silva, 2010, p. 98). Ainda que O Globo, por exemplo, tenha maior visibilidade 
em bairros onde moram outros segmentos sociais, cabe ressaltar que “[...] o destaque jornalístico conferido a esta ou aquela ocorrência diz respeito não tanto ao fato noticiado em si, mas a quem se sente, direta ou indiretamente, afetado por ele" (Silva, 2010, p. 159, grifos nossos). Há que se acrescentar, ainda, que a nova e atual abordagem jornalística da violência urbana se referencia no que se chama de cobertura segurança pública, o que contempla a “[...] apresentação de subsídios informativos [opinião de especialistas] que contribuam para a adoção de medidas pró-ativas, tendo em vista a manutenção da ordem e a paz social". ( Silva, 2010, p. 100)

Nesse cenário, O Globo divulgou, poucos dias depois, que a secretaria de segurança estudava uma nova forma de atuação no Alemão.

O secretário disse ontem que a polícia já planeja novas ocupações em quatro ou cinco lugares, mas está no momento reavaliando todas as condutas para que as ações sejam o menos traumáticas possível. Ele voltou a afirmar que a ocupação da Vila Cruzeiro não tem prazo para terminar. (O Globo, quinta-feira, 31, maio, 2007, p. 15, grifos nossos)

Os discursos dos integrantes do alto escalão do governo, que foram selecionados e noticiados pela imprensa, começavam a mostrar, pelo menos no plano discursivo, o reconhecimento da importância de não somente realizar uma mudança no modelo de combate aos bandos de traficantes que controlavam o comércio de drogas na região, mas de promover também ações sociais. O título de matéria publicada apresenta informações nesse sentido: "Guerra na Penha - Cabral promete ocupação social - Ação vai começar pelo Complexo do Alemão" (Extra, terça-feira, 5, junho, 2007, p. 11)

Passados 42 dias de operações policiais mais sistemáticas e constantes no Alemão, os jornais informavam que o conflito contabilizava números de mortos e feridos significativos; oficialmente, a quantidade já estava em torno de sessenta e quatro feridos e dezessete mortos. Somadas a esses números, eram noticiadas as insatisfação dos moradores com as ações de combate ao tráfico, solicitando que fossem modificadas a forma de atuação do Estado na região, e as recomendações de alguns especialistas acerca de outras estratégias de atuação policial. Seja por influência dos moradores e entidades de defesa dos 
direitos humanos, seja em razão da ação política da imprensa, seja por causa de estratégias estabelecidas pelo próprio governo - ou pela combinação parcial ou total desses fatores -, as mídias pesquisadas começaram a expor publicamente que o governo havia decidido promover modificações estratégicas na forma de atuação nas favelas do Alemão. Em vez de priorizar ações combativas diárias, decidiu-se pela ocupação dos os acessos às localidades.

\section{A Partir de Junho de 2007: a ocupação dos acessos ao Alemão e as novas propostas para a segurança pública}

Nesse período, após alguns meses de operações violentas, o governo decidiu ocupar as entradas/saídas das favelas da área. De acordo com a imprensa, a decisão foi tomada em reunião realizada na noite de 11 de junho entre o secretário de Segurança Pública, José Mariano Beltrame, o chefe da Polícia Civil, delegado Gilberto Ribeiro, e o comandante da PM, coronel Ubiratan Ângelo. Segundo um jornal, a "Polícia, enfim, muda estratégia. [...] A idéia é ocupar os acessos às comunidades e impedir que criminosos faturem com a venda das drogas". (Extra, quarta-feira, 13, junho, 2007, p. 13)

O objetivo central da operação, declarado à imprensa, era acabar com o controle territorial exercido pelos traficantes de drogas da região, causando prejuízos à facção local. Essa operação foi denominada "Cerco Amplo" e concretizou a diretriz principal da reunião supracitada, que anunciava promover, pelo menos em princípio, uma inflexão no modelo de ação policial no Alemão, no sentido de abrandar a perturbação na rotina dos moradores, o que representa um problema histórico na relação entre polícia e moradores de favelas (Machado da Silva; Leite, 2008b, p. 73-76). O debate público estruturado pela imprensa sugeria que se tencionava transitar de uma política de confronto para a ocupação dos acessos, com a finalidade de, gradualmente, enfraquecer a facção criminosa local.

Não obstante as mudanças estratégicas anunciadas pelo governo, a situação permaneceu violenta (Alves; Evanson, 2013, p. 51-144). Nesse sentido, vale expor como exemplo um trecho de uma matéria do jornal $O$ Globo na qual o repórter Alessandro Soler apresentou, de 
forma bem contundente, sua percepção sobre a situação vivida na localidade. É importante ressaltar que, nesta matéria, a rotina dos moradores foi representada de maneira destacada, o que não é comum no material pesquisado:

\section{Vivendo sob fogo cruzado numa zona de guerra}

Moradores da Vila Cruzeiro relatam a rotina de medo em meio aos confrontos entre policiais e bandidos [...]

Os 47 dias de confrontos entre policiais e traficantes nos complexos interligados de Vila Cruzeiro e Alemão, na Zona Norte, alteraram profundamente a rotina dos moradores. Cada um se protege como pode entre as trincheiras de uma guerra que, eles dizem, não tem precedentes naquela região. A restrição ao direito básico de ir e vir é apenas uma das faces mais visiveis do drama. Quem vive por ali se depara ainda com cenas de violência extrema, corpos, balas que atingem as casas. E tem de encarar a decadência de um lugar outrora próspero. (O Globo, domingo, 17, junho, 2007, p. 22, grifos nossos)

A violência policial no Alemão foi noticiada de maneira mais acentuada ainda na operação realizada no dia 27 de junho de 2007. Segundo os periódicos examinados, essa havia sido a maior mobilização policial já realizada no país, contando com um efetivo de 1.350 homens. Quanto aos resultados, os números oficiais apontavam um total de dezenove pessoas mortas somente nessa operação. (Burgos et al., 2011, p. 52)

Conforme mencionado nas seções anteriores, o acompanhamento diário das mídias impressas permite depreender que as ações no Alemão foram muito mais motivadas por considerações relacionadas a fatores históricos e estruturais do que a fatos isolados. Em outros termos, apesar de, no período de maio de 2007, as justificativas para as ações policiais nessa região apontarem para a morte de policiais em Oswaldo Cruz, as declarações públicas do secretário de segurança e outros integrantes do estafe do governo sugeriam, gradualmente, razões ligadas aos objetivos de enfraquecer ou desmobilizar a estrutura da facção criminosa que ocupava o local, mostrando que as ações policiais realizadas nessas favelas estavam, sobretudo, ligadas às representações do Alemão para o governo como um lugar de perigo imediato e de alta 
intensidade (Machado da Silva, 2012, p. 62), bem como um território central de irradiação da violência na cidade. O trecho da matéria abaixo ajuda a robustecer o argumento:

Beltrame afirmou que a operação [do dia 27 de junho] foi planejada durante meses com as informações levantadas pelo setor de inteligência das polícias e pelos policiais que vêm atuando há 50 dias na operação para asfixiar o tráfico no complexo. Segundo o secretário, a ação era necessária para enfraquecer a facção criminosa que atua no local, que seria a responsável por mais da metade dos crimes na cidade. (O Globo, quinta-feira, 28, junho, 2007, p. 14, grifos nossos)

O problema é que a proximidade dos Jogos Pan-Americanos do Rio de Janeiro - realizado entre os dias 13 e 29 de julho de 2007 - contribuiu para que críticas fossem feitas ao referido cerco policial porque havia a suspeita de que eram ações voltadas basicamente para atender o grande evento em questão. Um desses porta-vozes foi o presidente regional da OAB, Wadih Damous, que declarou temer que a operação do dia 27 de junho tivesse relação exclusiva com o Pan-Americano (Extra, sábado, 30, junho, 2007, p. 12). No entanto, o governador do Rio de Janeiro afirmou que se visava manter a ocupação da localidade por tempo indeterminado, mesmo depois dos jogos esportivos. Ademais, conforme já mencionado anteriormente, um dos periódicos pesquisados anunciava que "O governador quer também ampliar a presença do estado na comunidade, prestando serviços, como os previstos num convênio para 28 atividades esportivas na Vila Cruzeiro" (O Globo, quinta-feira, 14, junho, 2007, p. 15, grifos nossos). Esse mesmo discurso foi defendido publicamente pelo Secretário de Segurança Pública, reverberando na imprensa:

Na concepção do secretário, depois de a polícia "limpar", "extirpar" o tráfico, os moradores terão sua comunidade de volta, com o estado promovendo programas sociais. Em entrevistas ontem ao GLOBO, à Rádio CBN e ao "RJ-TV", da TV Globo, o secretário contou o seu sonho de fazer com que a população trabalhadora das comunidades volte a ter seu direito de ir e vir garantido (O Globo, sexta-feira, 29, junho, 2007, p. 18, grifos nossos) 
O Secretário de Segurança também procurou fazer declarações à mídia que desvinculavam as ações policiais no Alemão dos Jogos Pan -Americanos. Ao jornal O Globo falou que: “Pan é uma coisa; segurança pública do estado e da cidade é outra. São dois planejamentos totalmente diferentes. Um não tem comunicabilidade com outro. Temos que cuidar da cidade e do estado e fazer a nossa parte no Pan-Americano também". (O Globo, domingo, 1º, julho, 2007, p. 20)

Ainda que integrantes do governo procurassem desvincular publicamente as ações policiais no Alemão do Pan-Americano de 2007, a relação com os megaempreendimentos - não mais somente com os megaeventos - tornava a voltar à baila, em função de um projeto importante do governo federal que estava por ser colocado em prática: o Programa de Aceleração do Crescimento (PAC). As informações selecionadas e publicadas na imprensa expuseram que o referido Programa tinha previsão de iniciar ainda no final daquele ano (2007), com aporte de investimento em torno de R $\$ 485$ milhões somente para o Alemão e um total de R\$3,5 bilhões para o Estado (Extra, segunda-feira, 2, julho, 2007, p. 5). A ligação entre as ações policiais naquele contexto e o PAC tornou-se mais visível, através das mídias pesquisadas, com o fim do Pan-Americano e o início mais sistemático das discussões políticas para a viabilização do PAC, conforme a seguir:

Polícia prepara ação para pacificar o Alemão

Governo federal vai liberar verba para proteger 780 casas do Morro da Providência com material à prova de balas

[Repórter] Ana Cláudia Costa

Antes de o Complexo do Alemão se transformar num canteiro de obras, com a implementação do Programa de Aceleração do Crescimento (PAC), o conjunto de favelas deve passar por uma ação "pacificadora para erradicar a força armada". A afirmação foi feita ontem pelo secretário nacional de Segurança Pública, Antônio Carlos Biscaia, que esteve reunido ontem no Rio com o secretário de Segurança, José Mariano Beltrame, em mais um encontro do Grupo de Gestão Integrada (GGI). Biscaia acrescentou que, para essa operação, a ocupação dos acessos ao Complexo do Alemão por homens da Força Nacional será mantida até o fim do ano. 
Já está acertado como Ministério da Justiça que a Força Nacional dará apoio à ação de pacificação no Alemão e na Rocinha, para que possam ser iniciadas as obras do PAC - disse Biscaia. (O Globo, terça-feira, 25, setembro, 2007, p. 19, grifos nossos)

Além do objetivo de "pacificar" o Alemão, erradicando a força armada dos criminosos locais e tomando conta do território, com vistas à viabilização do PAC, outra questão importante começou a ganhar visibilidade. Ela concernia à relação entre policiais e moradores de favelas. Vale lembrar que a forma de atuação policial em favelas cariocas - agindo, não raramente, com a utilização de força desproporcional e indiscriminadamente sem distinguir entre morador e traficante (Machado da Silva; Leite, 2008) - não era um problema concernente só ao Alemão. Mas, como essa região estava no foco das ações policiais, a questão pululava na imprensa. Logo, por ocasião das operações nesse conjunto de favelas, os periódicos colocaram em pauta muitas reclamações e protestos de moradores e de órgãos de defesa da sociedade civil, no tocante à forma de atuação policial.

Uma matéria que exemplifica e dá visibilidade ao mencionado problema foi a que O Globo publicou sobre a forma de atuação da Força Nacional de Segurança Pública (FNSP). Segundo o jornal, a FNSP estava tendo melhor relação com os moradores do que a polícia militar, visto que utilizava abordagem e postura diferenciadas. De acordo com o que foi selecionado e divulgado pela mídia pesquisada, isso estava gerando, em certas situações, maior proximidade entre ambos:

[título] Força Nacional vira polícia modelo no morro. [subtítulo] Educação na hora da revista conquista moradores e é retribuída com água e café. [...] Em tom cordial, um tenente da Força Nacional de Segurança Pública aborda um morador que desce de moto a Favela da Grota, no Complexo do Alemão. [...] Os moradores já conversam com a gente. Contam cada história sobre os PMs que até nós ficamos impressionados - diz um policial de Brasília (O Globo, segunda-feira, 2, julho, 2007, p. 12, grifos nossos)

Sem supervalorizar o conteúdo da matéria já mostrada e generalizar o depoimento de um policial, é, no mínimo, interessante a posição 
dele, pois afirma que os moradores contam "histórias sobre os PMs". Não se deve negar o quanto tais "histórias" se fizeram presentes no transcurso das operações policiais no Alemão, no início do governo em apreço (Alves; Evanson, 2013, p. 51-144). Dessa forma, como consequência das ações policiais violentas nessa região e, especialmente, depois da mencionada grande operação do dia 27 de junho, a atuação policial nessa área foi colocada em grande evidência pública. A OAB, por exemplo, impetrou uma ação judicial para a realização da exumação dos dezenove corpos dos mortos em decorrência daquela grande operação, solicitando que se investigassem indícios de possíveis execuções realizadas pela polícia militar. Sobre essa matéria, o governador Cabral afirmou que "Nossa polícia recebe a orientação de respeitar a população e garantir a segurança". (O Globo, sexta-feira, 6, julho, 2007, p. 14)

A disputa entre o governo e entidades de defesa dos direitos humanos permaneceu, no caso dos dezenove mortos, pois o governo afirmava que todos eles eram criminosos e haviam sido mortos em confronto com policiais, mas as entidades nutriam suspeitas de que alguns policiais haviam cometido atos criminosos nessa operação, promovendo execução de pessoas. Como desdobramento da contenda, a situação ganhou exposição internacional e motivou a visita do representante da Organização das Nações Unidas (ONU), Philip Alston, que era o relator especial ONU sobre Execuções Arbitrárias, Sumárias e Extrajudiciais. Sobre a contenda, a imprensa pesquisada informou:

Alston criticou ontem duramente a política de segurança do governador do Rio, Sérgio Cabral (PMDB). Alston atacou principalmente a operação no Complexo do Alemão em 27 de junho, que resultou na morte de 19 pessoas (O Globo, quinta-feira, 15, novembro, 2007, p. 23).

Nesse contexto, as notícias relativas à política belicosa do governo no Alemão já tinham arrefecido. Entretanto, as marcas relativas à atuação policial na região ainda permaneciam e rendiam frutos, conforme se pode observar na visita do representante da ONU ao Brasil. Diante dessas questões, a parceria firmada entre os governos Federal e Estadual tomava importantes decisões, no tocante à preocupação 
com a atuação policial em favelas cariocas. Essas decisões apontavam para algumas discussões sobre mudanças na atuação policial nessas localidades, ainda que de maneira embrionária. Dessa forma, os jornais em análise selecionaram como fato importante a cerimônia de formação da primeira turma de mediadores de conflitos. Nesse curso, além de Juízes, Promotores, Defensores Públicos, participaram também Policiais, Guardas Municipais e mais de 500 líderes comunitários do Rio de Janeiro. O jornal informava que "[Eles] vão receber amanhã, no auditório do Ministério Público Estadual, o diploma de conclusão do curso de mediação e resolução pacífica de conflitos". (O Globo, domingo, 2, dezembro, 2007, p. 27, grifos nossos)

Em adição, no início de 2008, um dos jornais examinados informava que a Força Nacional de Segurança Pública não iria mais sair do Alemão (Extra, domingo, 13, janeiro, 2008, p. 24). Mostrava, ainda, a previsão da ocupação efetiva da região para a implantação do PAC e do Programa Nacional de Segurança Pública com Cidadania (PRONASCI). Vale lembrar que uma das diretrizes do PRONASCI era, com base na parceria entre as esferas Federal, Estadual e Municipal, procurar garantir os direitos constitucionais dos cidadãos brasileiros colocando em prática os princípios de um modelo de polícia comunitária. (Alves; Evanson, 2013, p. XVII)

Quase desnecessário afirmar que não há o interesse, aqui, em discutir se houve ou não mudança fática no que se refere à atuação policial ou em quaisquer outras determinações normativas apontadas como sugestões para a política de segurança que, paulatinamente, foram sendo tematizadas. Intenta-se, sim, colocar em realce que algumas medidas começaram a ser propostas, ainda que em estágio rudimentar, e, por isso, foram retomadas à frente.

\section{Novembro e Dezembro de 2008: a estruturação de um novo modelo de policiamento na favela Santa Marta}

Faço uma breve excursão temporal, neste ponto, no sentido de provocar uma visão comparativa entre a política de segurança do supracitado governo no seu primeiro ano (2007) e a que foi colocada em prática a partir do final do segundo ano. A ocupação da favela Santa 
Marta, ocorrida desde 19 de novembro de 2008, não foi relatada com grande alarde pelos jornais consultados, pelo menos nos primeiros dias. Em matéria sem muito destaque, $O$ Globo descreveu que a polícia havia ocupado a localidade e que intentava combater o tráfico e estabelecer a ordem na favela. Assim:

De acordo com o tenente-coronel Albuquerque, comandante do $2^{\circ} \mathrm{BPM}$ (Botafogo), a ordem do comando da PM é manter o morro ocupado por tempo indeterminado. Com a polícia na comunidade, explicou, equipes de fornecimento de água, energia e limpeza urbana, entre outros serviços, vão poder trabalhar com tranqüilidade. (O Globo, quinta-feira, 20, novembro 2008, p. 17, grifos nossos)

Somente passado alguns dias dessa ocupação é que as mídias pesquisadas expuseram declaração do Secretário de Segurança Pública, José Mariano Beltrame, informando alguns procedimentos pensados para a localidade:

Vamos criar uma nova maneira de policiamento comunitário, com uma nova nomenclatura. Segurança pública não é somente ações policiais. Precisamos que o estado entre com os serviços. É importante que as pessoas tenham dignidade - disse o secretário (O Globo, sexta-feira, 28, novembro, 2008, p. 15, grifos nossos).

Segundo a mídia, o novo modelo de policiamento estabelecido na favela Santa Marta ainda estava se estruturando. Conforme o Secretário de Segurança:

É um laboratório, um modelo de política de segurança pública. Estamos fazendo planilhas com os gastos. Vamos apresentar à sociedade os resultados e dizer: deu certo, esse é o custo. Se vocês quiserem um policiamento igual no Complexo do Alemão, vai custar tanto - disse Beltrame. (O Globo, quarta-feira, 3, dezembro, 2008, p. 13, grifos nossos)

Em resumo, as finalidades declaradas com a ocupação policial da favela Santa Marta foram, gradativamente, sendo tornadas públicas pelos integrantes do governo. Com isso, as mídias examinadas passaram cada vez mais a selecionar, noticiar e valorizar a ocupação 
policial da favela, realizando isso com crescente destaque. Conforme já discutido em outro artigo (Palermo, 2013, p. 316-317), de forma sinóptica, os principais objetivos da referida ocupação policial que reverberaram na imprensa pelas declarações dos mais destacados integrantes do governo foram: a retomada do território controlado por traficantes de drogas, para que se pudesse promover a entrada cada vez mais intensa de serviços sociais e de infraestrutura porque, segundo o discurso governamental escolhido e iluminado pela mídia, a promoção de serviços nas favelas era dificultada ou obstaculizada pela presença de traficantes de drogas nas localidades. Além disso, tendo em vista os constantes problemas relativos à atuação policial em favelas - vide exemplo do Alemão exposto nas seções anteriores -, um novo modelo de policiamento foi anunciado pelo governo para ser colocado em prática na favela Santa Marta, contemplando o policiamento comunitário, segundo o próprio Beltrame. (O Globo, terça-feira, 16, dezembro, 2008, p. 21 )

Como consequência de tais objetivos, a imprensa divulgava, à época, que havia sido planejado pelo governo a implantação de uma Companhia de Policiamento Comunitário na localidade, com o fito de garantir a presença constante da polícia militar na favela, assegurando, pelo menos em princípio, a redução ou o fim dos confrontos armados entre traficantes e policiais que eram causadores de alta letalidade, conforme exposto na matéria a seguir:

A tomada da favela

Depois de anos dominado pelo tráfico, o Morro Dona Marta foi ocupado [...] pela Polícia Militar sem a necessidade de um tiro sequer. Ao todo, 50 homens passaram a patrulhar diariamente a comunidade: policiais militares do $2^{\circ} \mathrm{BPM}$ (Botafogo), do Batalhão Florestal e da Companhia de Cães da PM. Todas as "bocas-de-fumo" fecharam e os traficantes fugiram para outras favelas.

Já nos primeiros dias, os efeitos da ocupação chegaram ao asfalto: o número de roubos e furtos nas ruas de Botafogo junto ao acesso do Dona Marta despencou. A Secretária de Segurança anunciou que o plano é manter ocupações semelhantes em outras favelas. (O Globo, segunda-feira, 15, dezembro, 2008, p. 15, grifos nossos) 
O destaque dado pelo $O$ Globo para a ausência de tiro na ocupação da favela Santa Marta pela polícia militar começava a marcar uma inflexão no modelo de cobertura da mídia, pois este passaria crescentemente a tematizar as localidades ocupadas pela polícia militar por outras metáforas: da "guerra" transitava-se para a "paz" (Leite, 2012). Portanto, olhando em retrospectiva, podemos vislumbrar tais mudanças e apontar, por outro lado e a partir da imprensa, para certos elementos de continuidade, pois, conforme procurei realçar no transcurso das operações violentas no Alemão, a base dos objetivos declarados para a ocupação da Santa Marta havia sido, em muitas ocasiões, colocada em discussão e/ou prática por conta das ações policiais constantes e violentas no Alemão.

Cumpre reiterar que não intentei afirmar que os discursos/sugestões que foram selecionados e publicados pela mídia, na ocasião das ações policiais no Alemão, eram novos em si. Procurei pontuar que se tratava de algo novo no contexto da política de segurança que o governo praticava, especialmente no início de 2007. Afirma-se isso porque a "UPP é, [...], filha de uma história de fracassos de experiências de policiamento especializado para favelas. Isto não significa que muitas dessas experiências não contivessem virtudes que mais tarde serão incorporadas ao modelo da UPP". (Burgos et al., 2011, p. 53)

\section{Considerações Finais}

O debate público acerca da violência urbana (e das ações de combate a ela) encontra nas diversas mídias canais de reverberação que organizam e hierarquizam informações e discursos. O levantamento de dados acerca das ações policiais no Alemão, no decorrer do ano de 2007, e a averiguação de como foram constituídos os primeiros passos da ocupação da favela Santa Marta (novembro e dezembro de 2008), considerada institucionalmente a primeira UPP, permitem, a partir da grande imprensa escrita, a análise de uma perspectiva social e política importante acerca de alguns discursos que contribuíram para a construção da segurança pública do governo em apreço.

Partindo da premissa de que as UPPs foram inventadas como um processo e um aprendizado (Fleury, 2012, p. 199), foram apre- 
sentados aspectos importantes da referida política de segurança para favelas cariocas. As informações e discursos selecionados, organizados e publicados pela imprensa escrita pesquisada indicam que o modelo de ação policial eminentemente belicoso, dirigido aos Complexos do Alemão e da Penha, nos primeiros anos desse governo, provinha da consideração de que a região era o foco irradiador da violência na cidade do Rio de Janeiro, o que correspondeu a um “[...] claro exemplo do encontro entre representação, construção de problemas públicos e políticas de intervenção [policial violentas]". (Machado da Silva; Leite, 2008b, p. 50)

Com relação às representações do Alemão para a cidade, foi sugerido que, ao selecionar, hierarquizar e divulgar informações sobre a política de segurança do governo, a imprensa contribuiu para organizar tanto a percepção social sobre as representações do Alemão como um lugar de perigo, como também, em sentido mais amplo, para pautar o debate público sobre tais representações. E essa é uma das formas de a imprensa agir politicamente.

Como consequência da capacidade de ação da imprensa para organizar a percepção social e interferir no debate público, foi indicado como a mídia pesquisada não somente selecionou e divulgou a gradual mudança na política de segurança do governo, como também cooperou para influenciar - ainda que em certa medida, cabe mencionar - nas pontuais transformações da referida política, pautando publicamente debates e questões que foram, de forma crescente, ganhando visibilidade e sendo incorporadas ao discurso do governo.

Procurei mostrar, portanto, como, na imprensa pesquisada, as ações policiais no Alemão (2007) foram contribuíram para a estruturação gradativa de um modelo de policiamento que foi sistematizado e colocado em prática na favela Santa Marta (2008). Logo, a ocupação territorial para se promover serviços sociais, tendo por base uma polícia formada em novo modelo e com nova forma de atuação, foram questões/sugestões colocadas no contexto das ações belicosas no Alemão. E foram esses postulados basilares, conforme se pode captar nas informações e discursos que foram publicados na mídia, que deram uma linha de pensamento e ação para a ocupação da favela Santa Marta, 
o que apresenta, em certa medida, uma continuidade em relação ao período anterior à referida ocupação.

Por fim, vale reiterar que não foi postulado que as mudanças apontadas na política de segurança pública partiram da imprensa ou que foram realizadas exclusivamente por conta de sua atuação, mas sim que ela estruturou um debate público acerca desse campo. Com isso, acabou organizando questões e debates que interferiram na sociedade e, em alguma medida, no curso das ações políticas. Nesse sentido, de acordo com Fausto Neto (2004, p. 120), a mídia, na atualidade, “[...] se converte, segundo estratégias discursivas distintas em dispositivos que não só narram, mas agem sobre o espaço político".

\section{Notas}

1 Doutorando do Programa de Pós-Graduação em Ciências Sociais/PPCIS da Universidade do Estado do Rio de Janeiro (UERJ), com bolsa de estudos da FAPERJ.

2 Ao se referir ao termo grande imprensa, estou abordando uma amostragem da parcela que é mais visível, em termos de mercado. Não se trata de pensar a imprensa, nem a grande imprensa, como uma instituição homogênea e capaz de impor um modelo ou pensamento unidimensional. Trata-se, sim, de situar aqui parcela da imprensa que, pela característica de seu trabalho, em alguma medida tem influência na vida social, política, econômica e cultural da cidade. Tudo isso tendo em conta, ainda, a inter-relação produtores de mídia e seus leitores.

3 A pesquisa da qual participei é parte do projeto denominado "Virtudes e Limites das UPPs: uma avaliação socioantropologica", que foi colocado em prática sob coordenação do Prof. Dr. Luiz Antonio Machado da Silva, com financiamento da Faperj. Devo meu agradecimento ao referido Professor e à Prof ${ }^{\mathrm{a}}$. Dra ${ }^{\mathrm{a}}$. Lia de Mattos Rocha, que foi quem me convidou para participar da pesquisa e quem dirigiu os trabalhos e a equipe. É importante mencionar ainda que a equipe de trabalho foi composta por Diego Calmon, Eduardo Ramos e Raquel Fabeni. Os pesquisadores envolvidos externam também seus agradecimentos ao Centro de Documentação e Informação do InfoGlobo, que reúne os jornais O Globo, Extra e Expresso, os sites Globo e Extra, bem como a Agência O Globo, mencionando, em especial, Fabio Ponso, Ana Cristina Tavares, Monica Lessa e Paulo Luiz.

\section{Referências}

ALVES, Maria Helena Moreira; EVANSON, Philip. Vivendo no fogo cruzado: moradores de favela, traficantes de droga e violência policial no Rio de Janeiro. 1. ed. São Paulo: Editora Unesp, 2013.

BECKER, Howard. Segredos e truques da pesquisa. Rio de Janeiro: Zahar, 2007. 
BOURDIEU, Pierre. O poder simbólico. 13. ed. Rio de Janeiro: Bertrand Brasil, 2010.

. Sobre a televisão. Rio de Janeiro: Jorge Zahar Editor, 1997.

BORGES, Wilson Couto. Criminalidade no Rio de Janeiro: a imprensa e a (in)formação da realidade. Rio de Janeiro: Revan, 2006.

BURGOS, Marcelo Baumann et al. O efeito UPP na percepção dos moradores de favelas. Revista de Ciências Sociais Desigualdade $\boldsymbol{\sigma}$ Diversidade, Rio de Janeiro, PUC, n. 11, ago.-dez. p. 49-98, 2011.

BURGOS, Marcelo Baumann. Dos parques proletários: as políticas públicas nas favelas do Rio de Janeiro. In: ZALUAR, Alba; ALVITO, Marcos (Org.). Um século de favela. Rio de Janeiro, FGV, 1998. p. 25-60.

DE LUCA, Tania Regina. Fontes impressas: História dos, nos e por meio dos periódicos. In: PINSKY, Carla Bassanezi. (Org.). Fontes históricas. 3. ed. São Paulo: Contexto, 2011 .p. $111-154$.

FARIAS, Juliana. Da asfixia: reflexões sobre a atuação do tráfico de drogas nas favelas cariocas. In: SILVA, Luiz Antonio Machado da (Org.). Vida sob cerco: violência e rotina nas favelas do Rio de Janeiro. Rio de Janeiro: Nova Fronteira, 2008. p. 173-190.

FAUSTO NETO, Antônio. Comunicação e mídia impressa: estudo sobre a Aids. São Paulo: Hacker Editores, 1999.

. Discurso político e mídia. In: RUBIM, Antonio Albino. (Org.).

Comunicação e política: conceitos e abordagens. 1. ed. São Paulo: Edufba, 2004. v. 1, p. 105-126.

FLEURY, Sônia. Militarização do social como estratégia de integração: o caso da UPP do Santa Marta. Sociologias, Porto Alegre, ano 14, n. 30, maio-ago., p. 194-222, 2012.

FOUCAULT, Michel. A ordem do discurso. São Paulo: Loyola, 1996.

. Verdade e poder. In: Microfísica do poder. Tradução de Roberto Machado. Rio de Janeiro: Edições Graal, 1979.

Vozes, 2011.

. Vigiar e punir: nascimento da prisão. 39. ed. Petrópolis, RJ:

. O que são as Luzes? In: Ditos e Escritos II: Arqueologia das

Ciências e História dos Sistemas de Pensamento. Rio de Janeiro: Forense Universitária, 2008a. p. 335-351.

LEEDS, Anthony; LEEDS, Elizabeth. A sociologia do Brasil urbano. Rio de Janeiro, Zahar, 1978. 
LEEDS, Elizabeth. Cocaína e poderes paralelos na periferia urbana brasileira: ameaças à democratização em nível local. In: ZALUAR, Alba; ALVITO, Marcos (Org.). Um Século de Favela. Rio de Janeiro, Ed. Fundação Getúlio Vargas, 2003

LEITE, Márcia Pereira. Da metáfora da guerra ao projeto de pacificação: favelas e políticas de segurança pública no Rio de Janeiro. Revista Brasileira de Segurança Pública, São Paulo, v. 6, n. 2., ago.-set., p. 374389, 2012.

. Entre o individualismo e a solidariedade: dilemas da política e da solidariedade no Rio de Janeiro. Revista Brasileira de Ciências Sociais, Rio Grande do Sul, v. 15, n. 44, outubro, p. 73-90, 2000.

MACHADO DA SILVA, Luiz Antonio. A continuidade do problema favela. In: OLIVEIRA, Lucia Lippi (Org.). Cidade: história e desafios. Rio de Janeiro: Editora FGV, 2002. p. 220-237.

MACHADO DA SILVA, Luiz Antonio; LEITE, Márcia P. Favelas e democracia: temas e problemas da ação coletiva nas favelas cariocas. In: Rio: a democracia vista de baixo. IBASE Rio de Janeiro: IBASE, 2004. p. 61-77.

. Violência urbana, sociabilidade violenta e agenda pública. In: SILVA, Luiz Antonio Machado da (Org.). Vida sob cerco: violência e rotina nas favelas do Rio de Janeiro. Rio de Janeiro: Nova Fronteira, 2008a. p. 35-46.

. Violência, crime e polícia: o que os favelados dizem quando falam desse temas?. In: SILVA, Luiz Antonio Machado da (Org.). Vida sob cerco: violência e rotina nas favelas do Rio de Janeiro. Rio de Janeiro: Nova Fronteira, 2008b. p. 47-76.

. Afinal, qual é a das UPPs. [2010]. Disponível em: <www. observatoriodasmetropoles.ufrj.br $>$. Acesso em: $1^{\circ}$ mar. 2010.

. A partir do relatório SAGMACS: as favelas, ontem e hoje. In: MELLO, Marco Antonio da Silva et al. (Org.). Favelas cariocas ontem e hoje. Rio de Janeiro: Garamond, 2012. p. 51-65.

PALERMO, Luis Claudio. Megaeventos e Unidades de Polícia Pacificadora: representações sobre o lugar das favelas no tecido urbano. Ilha - Revista de Antropologia, Florianópolis, v. 15, n. 2, jul.-dez. 2013. p. 311-330.

PARISSE, Luciano. Favelas do Rio de Janeiro: evolução e sentido. Rio de Janeiro: Centro Nacional de Pesquisas Habitacionais - CENPHA, 1969. 
ROCHA, Lia de Mattos. “Uma favela sem tráfico? Os limites da ação e da opressão do tráfico. In: SILVA, Luiz Antonio Machado da (Org.). Vida sob cerco: violência e rotina nas favelas do Rio de Janeiro. Rio de Janeiro: Nova Fronteira, 2008. p. 191-226.

RONDELLI, Elizabeth. Imagens da violência e práticas discursivas. In: PEREIRA, C. Alberto Messeder et al. (Org.). Linguagens da violência. Rio de Janeiro: Rocco, 2000. p. 144-162.

RIO DE JANEIRO. Governo do Estado. Unidade de Polícia Paicifcadora (UPP). [2013]. Disponível em: < http://www.upprj.com/ index.php/o_que_e_upp>. Acesso em: $18 \mathrm{dez} .2013$.

RIO DE JANEIRO. Governo do Estado. Unidade de Polícia Paicifcadora (UPP): Santa marta. Disponível em: < http://www.upprj.com/index.php/ informacao/informacao-interna/Santa\%20Marta $>$. Acesso em: $1^{\circ}$ mar. 2010.

SILVA, Edilson Márcio Almeida da. Notícias da violência urbana: um estudo antropológico. Niterói: Editora da Universidade Federal Fluminense, 2010.

SILVA, Maria Lais Pereira da. Favelas cariocas: 1930-1964. Rio de Janeiro: Contraponto, 2005.

VALLADARES, Lícia do Prado. A invenção da favela: do mito de origem a favela.com. Rio de Janeiro: Editora FGV, 2005.

ZALUAR, Alba e ALVITO, Marcos. (Org.). Um século de favela. Rio de Janeiro: FGV, 1998.

ZALUAR, Alba. A máquina e a revolta: as organizações populares e o significado da pobreza. 2. ed. São Paulo: Brasiliense, 2000. 